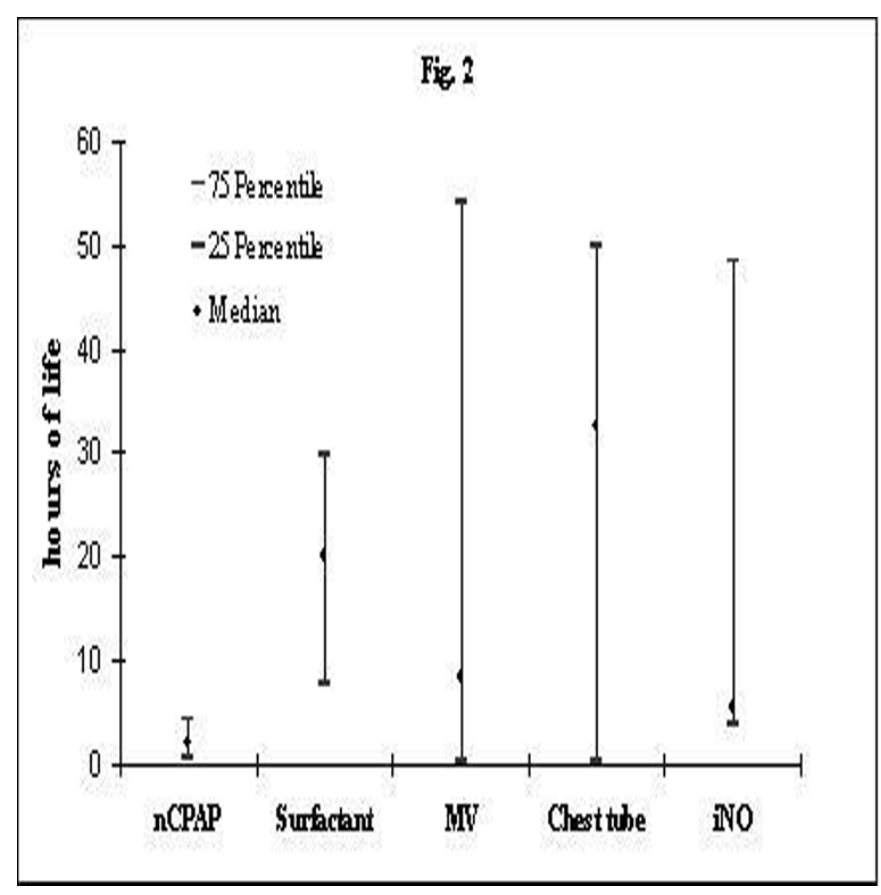

[fig 2]

1345

\section{THE USE OF HOOD CPAP TO IMPROVE COMPLIANCE WITH NON-INVASIVE VENTILATION (NIV): A SINGLE CENTRE EXPERIENCE}

\author{
C. Ronan ${ }^{1}$, C. Turton ${ }^{2}$, M. Vaidya ${ }^{3}$, \\ S. Thyaga Rajan ${ }^{3}$
}

${ }^{1}$ Paediatric Respiratory Physiotherapy, ${ }^{2}$ Paediatric Critical Care Unit Nursing, ${ }^{3}$ Paediatric Critical Care Unit, Barts and the London Children's Hospital,

$$
\text { London, UK }
$$

Background: The Ca-Star CPAP (Continuous Positive Airway pressure) Hood is a relatively novel method of delivering CPAP to infants and children.

Aims: To report the experience of a single centre in the application of Hood CPAP for provision of NIV.

Methods: We retrospectively analysed all children admitted to a six bedded PCCU for NIV over a 2 year period. Children included in the study were those who had failed conventional mask CPAP yet gone on to tolerate Hood CPAP for $>24$ hours or until NIV was no longer required.

Results: Six patients (4 males) were identified with mean age of 14 months (range 6 months - 3 years). The reasons for failing conventional CPAP were pressure areas on face (1), child intolerance of mask pressing on face (4) and inability to get seal due to facial abnormalities (1).

The indications for CPAP included primary Respiratory condition (5) and neuromuscular (1). The underlying co-morbidities were ex pre-maturity (2), Trisomy 21 (2), congenital abnormalities (1) and none (1). Hypothermia was observed as a complication in 2 patients.

Conclusions: Intolerance of the mask is a problem in the 'toddler' age range, and in our experience the HOOD is an under-utilised but useful interface to provide CPAP in these patient groups. It can be used successfully as an alternative to intubation, for relief of facial pressure areas and to provide an effective seal in case of facial abnormalities.

\section{6}

\section{FLUTISANE PROPIONATE IN PREVENTION OF RHYNITIS ALERGICA WITH CHILDREN}

\author{
I. Timovski, V. Angelovska
}

\section{Paediatric Dispensary, Military Hospital, Skopje, FYR Macedonia}

Introduction: In childhood rhynitis alergica is medical and social problem. The nasal mucous membrane first gets in touch with a lot of causes, including causes of allergy.

Objective: Improvement of quality of the life with children who are treated with Fluticasone propionate.

Material and methods: We processed the data from medical records of 58 children on the age of 6 and 12 years in the period of 2 years ( 2008 - 2009), and 43 children from them were put on prevention with Fluticasone propionate. For processing the data we used analytic and descriptive method.

Results: We processed 58 cases with rhynitis alergica proved with: skin tests or RIDA screen tests, total lgE, eosinophyles in nose and drainage secretion. 15 children were put only on symptom's therapy,and 43 children were put on therapy with Fluticasone propionate in a period of a few months. With 9 children rhinitis alergica was followed by conjuctivitis alergica and they get antihistaminic medicaments. All children that were put on prevention had minimal symptoms of Rhynitis and they had normal physical activities and attend a school regularly. 
Conclusion: Suitable and therapy on time allows normal and healthy life and free activity with children who have proved rhynitis alergica.

\section{7}

\section{NON INVASIVE VENTILATION IN PEDIATRIC INTENSIVE CARE UNIT}

\author{
I. Tassiou, K. Papazoglou, A. Patsoura, \\ J. Papadatos \\ PICU, P\&A Kyriakou Pediatric Hospital, \\ Athens, Greece
}

Objective: The aim of this study was to investigate the benefit of the Non Invasive Ventilation (NIV) in children admitted to the Pediatric Intensive Care Unit (PICU).

Methods: We studied 22 children supported by NIV, aged 1 month to 15 years. The duration of the study was 4 years (January 2006- December 2009). The total number of admissions to ICU during this period was 759 (2,9\% supported by NIV).

The causes of the respiratory failure in these children supported by NIV were: chronic diseases-infection $(n=11 ; 50 \%)$, neuromuscular diseases $(n=4$; $18,18 \%$ ), renaltransplantations-immunosuppression $(n=3 ; 13,63 \%)$, leukemias $(n=2 ; 9,09 \%)$, respiratory infections $(n=2 ; 9,09 \%)$.

We selected the Biphasic Ventilation mode (Bi-Vent) by facial mask, because our patients were in severe respiratory distress. The parameters in this mode were as follow: PIP: $10-16 \mathrm{cmH} 2 \mathrm{O}$ and PEEP 6-12 $\mathrm{cmH} 2 \mathrm{O}$. The mean duration of NIV was 4 days (3 hours to 14 days).

Results: Facial mask was well tolerated and with no injuries from her use. Results showed that 19 patients $(86,36 \%)$ recovered and 3 patients $(13,63 \%)$ died because of their underlying disease and not from the respiratory failure. Two of our patients continued the NIV ventilation as home care treatment.

Conclusions: NIV support of respiratory failure is a very useful tool in the pediatric intensivists' hands because it is good alternative to mechanical ventilation. It is well tolerated, reduces the need of sedation and the PICU stay in these patients.
1348

\section{INFLUENZA A H1N1 VIRUS INFECTION IN A PEDIACTRIC INTENSIVE CARE UNIT}

\section{P. Neto, P.V. Silva, S. Santos, C. Pinto, A. Dinis, L. Carvalho, F. Neves \\ Pediatric Intensive Care Unit, Hospital Pediátrico de Coimbra - Centro Hospitalar Coimbra, Coimbra, Portugal}

Background: the main form of clinical presentation in critically ill patients with $\mathrm{H} 1 \mathrm{~N} 1$ infection is rapidly progressive respiratory failure, shock, neurological involvement and renal failure. Children with comorbidity and aged $<2$ years are at particular risk.

Methods: a descriptive, retrospective study on the clinical presentation and management of patients with H1N1 infection was performed in a Pediatric Intensive Care Unit (PICU). All children admitted in PICU of Coimbra's Pediatrics Hospital $(\mathrm{CPH})$ were described, from July $15^{\text {th }}$ to November $30^{\text {th }}$ of 2009 .

Results: during this period, 241 children with laboratory confirmation of $\mathrm{H} 1 \mathrm{~N} 1$ infection were observed in $\mathrm{CPH}$, of whom $38(16 \%)$ required hospitalization, $4(1.7 \%)$ in PICU-CPH. The age ranged from 4 months to 21 years. Three patients had previous co-morbidities. All met clinical criteria for $\mathrm{H} 1 \mathrm{~N} 1$ infection and were admitted with respiratory distress (4), rapidly progressive and evolution to ARDS (2), associated with shock (2) and lethargy (2). Three patients required mechanical ventilation (conventional and high-frequency oscillatory ventilation); the duration ranged between 4-12 days. Two patients received intravenous catecholamines support, two developed acute renal failure and two had pancytopenia. There were two bacterial coinfections. All received treatment with oseltamivir. Length of PICU stay ranged from 5-22 days, with a favorable outcome in all cases.

Conclusion: in the 1st peak of $\mathrm{H} 1 \mathrm{~N} 1$ outbreak, $10 \%$ of the hospitalized children required PICU admission. Despite severe respiratory disease and multiple organ dysfunction, a good outcome was achieved, with no mortality. 